\title{
GAYA PENGASUHAN ORANGTUA DENGAN PERILAKU BERMASALAH PADA ANAK TAMAN KANAK-KANAK (TK)
}

\author{
Amadhea Septining Tyas ${ }^{1}$ \\ Agnes Maria Sumargi ${ }^{2}$
}

Fakultas Psikologi, Universitas Katolik Widya Mandala Surabaya

\begin{abstract}
Abstrak
Anak-anak usia dini kerap menunjukkan perilaku bermasalah seperti berkelahi dan menyakiti orang lain serta menunjukkan kecemasan. Salah satu faktor yang mempengaruhi perilaku bermasalah adalah gaya pengasuhan orangtua. Secara teoritis, gaya pengasuhan terbagi menjadi gaya pengasuhan otoritatif, otoriter, dan permisif. Gaya pengasuhan otoriter dan permisif cenderung mempengaruhi anak secara negatif, sedangkan gaya pengasuhan otoritatif mempengaruhi anak secara positif. Penelitian mengenai gaya pengasuhan dan perilaku bermasalah anak usia dini relatif masih kurang, oleh karena itu tujuan penelitian ini adalah menguji hubungan gaya pengasuhan orangtua dengan perilaku bermasalah anak TK. Subjek dalam penelitian ini adalah 71 orangtua dari anak yang bersekolah di TK X dan TK Y Surabaya. Alat ukur yang digunakan berupa skala yang diisi orangtua, yakni Parenting Style and Dimension Questionnaire (PSDQ) untuk mengungkap gaya pengasuhan orangtua dan Strength and Difficulties Questionnaire (SDQ) untuk mengungkap perilaku bermasalah anak. Hasil penelitian ini menunjukkan korelasi antara gaya pengasuhan otoritatif dengan perilaku bermasalah pada anak sebesar $-0,049, p=563(p>0,05)$, sedangkan korelasi antara gaya pengasuhan otoriter dengan perilaku bermasalah anak adalah sebesar $0,336, p=0,000(p<$ $0,05)$ dan korelasi antara gaya pengasuhan permisif dengan perilaku bermasalah pada anak adalah sebesar $0,267, p=0,002(p<0,05)$. Hal ini menunjukkan hanya gaya pengasuhan otoriter dan permisif yang memiliki hubungan yang signifikan dengan perilaku bermasalah pada anak TK. Semakin sering orangtua menggunakan gaya pengasuhan otoriter dan permisif, maka semakin tinggi tingkat perilaku bermasalah anak, dan sebaliknya, semakin jarang orangtua menggunakan gaya pengasuhan otoriter dan permisif, maka semakin rendah pula tingkat perilaku bermasalah anak.
\end{abstract}

Kata kunci : anak usia dini, gaya pengasuhan orangtua, perilaku bermasalah.

\begin{abstract}
Young children usually show emotional and behavioural problems, such as fighting and aggression, and showing anxiety. Parenting style is one of the factors that influence behavioural problems. Theoretically, parenting style is divided into authoritative, authoritarian, and permissive parenting. Authoritarian and permissive parenting influence children in a negative way, while authoritative parenting influences children in a positive way. Studies regarding the impact of parenting style on young children's emotional and behavioural problems are limited; therefore, the purpose of this study was to examine the relationship between parenting styles and behavioural problems of kindergarten students. Participants were 71 parents of children at kindergarten $X$ and $Y$ in Surabaya. Parents completed parenting and child behavior measures, i.e. Parenting Style and Dimension Questionnaire (PSDQ) to measure parenting style and Strength and Difficulties
\end{abstract}


Questionnaire (SDQ) to measure child emotional and behavioral problems. Results showed a correlation coefficient of $-0,049, p=0,563(p>0,05)$ for authoritative parenting and child emotional and behavioural problems, a correlation coefficient of $0,336, p=0,000(p<0,05)$ for authoritarian parenting and child emotional and behavioural problems, and a correlation coefficient of 0,267, $p=0,002(p<0,05)$ for permissive parenting and child emotional and behavioural problems. This indicates that only authoritarian and permissive parenting had significant relationships with child emotional and behavioural problems. The more frequent parents used authoritarian and permissive parenting, the higher the levels of child emotional and behavioral problems, and vice versa, the less frequent parents used authoritarian and permissive parenting, the lower the levels of child emotional and behavioral problems.

Keywords : young children, parenting style, behavioral problems.

Bagi sebagian besar orang, Taman kanak-kanak (TK) merupakan jenjang pendidikan awal bagi anak sebelum mereka memasuki sekolah dasar (SD). Oleh sebab itu, pengalaman anak selama berada di TK dapat berpengaruh bagi perkembangan anak selanjutnya. Menurut Erikson (dalam Santrock, 2014), perkembangan anak TK yang umumnya berusia 3-5 tahun berada pada tahap ketiga dari perkembangan psikososial, yaitu inisiatif versus rasa bersalah. Pada tahap ini, anak mulai menghadapi dunia sosial yang luas dan mulai bereksplorasi. Anak berperan secara aktif dan menunjukkan inisiatif yang tinggi. Apabila inisiatif ini dihalangi oleh lingkungan (orangtua dan guru di sekolah), terlebih jika inisiatif tersebut menyebabkan diberikannya hukuman pada anak, maka anak mengembangkan perasaan bersalah dan menjadi takut untuk mencoba hal-hal yang baru. Kondisi ini dapat mempengaruhi tahap perkembangan selanjutnya.

Selain itu menurut Havighurst (dalam Hurlock, 1997), anak usia dini memiliki tugastugas perkembangan, antara lain memahami hal yang baik dan buruk, belajar mengenali emosi dan berhubungan dengan lingkungan sekitar, serta membentuk konsep sederhana mengenai realitas sosial fisik. Anak dapat menjalankan tugas-tugas perkembangan tersebut dengan bantuan lingkungan sekitar. Dengan demikian, pengalaman anak selama di sekolah bersama dengan guru dan teman-temannya, dan juga di rumah bersama dengan orangtua dan pengasuhnya dapat mempengaruhi perkembangan psikologis anak yang kemudian muncul dalam bentuk perilaku.

Idealnya, perilaku aktif anak dapat terkontrol dan bersifat positif, artinya tidak menganggu orang lain di sekitarnya dan anak dapat menyesuaikan diri dengan aturan yang ada. Namun pada kenyataannya, banyak anak usia prasekolah mengalami hal-hal seperti kurang mau bekerja sama dan kurang tanggap terhadap orang-orang dewasa, dan memiliki kompetensi sosial yang kurang, seperti kurang sopan, kurang patuh terhadap tuntutantuntutan, sulit untuk diam dan fokus dengan yang dikerjakan (Santrock, 2014). Berdasarkan hasil temuan peneliti di lapangan diketahui bahwa anak TK memunculkan perilaku bermasalah seperti agresi, mengganggu orang lain, berlaku kurang sopan, dan tidak patuh pada aturan. Hal tersebut sama dengan temuan Izzaty dan Nuryoto (2006) bahwa perilaku bermasalah yang umumnya dijumpai pada anak TK adalah agresivitas, kecemasan, temper tantrum, kesulitan berkomunikasi, menarik diri, berbohong, malu, menangis, dan takut.

Menurut Jessor dan Jessor (dalam Spoth, Neppl, Lillehoj, \& Jung, 2006), perilaku bermasalah adalah perilaku yang didefinisikan secara sosial sebagai sebuah masalah yang dapat memunculkan keprihatinan dari lingkungan atau sebagai perilaku yang tidak diinginkan oleh norma yang berlaku dan biasanya jika terjadi menimbulkan semacam respon kontrol sosial. Perilaku bermasalah dapat dibagi menjadi dua kelompok, yaitu eksternalisasi yang pada dasarnya adalah masalah perilaku seperti: perhatian mudah teralihkan dan tidak bisa 
diam (hiperaktif), marah meledak-ledak dan berkelahi dengan anak lain, dan internalisasi yang pada dasaranya adalah masalah emosi seperti: mudah menangis dan cemas, serta cenderung menyendiri (Achenbach, 1991 dalam Akhter, Hanif, Tariq, \& Atta, 2011; Goodman, 1997). Perilaku eksternalisasi mengacu pada sekelompok kondisi yang ditandai dengan agresi, kenakalan, dan hiperaktivitas (Liu, 2004 dalam Akhter dkk., 2011). Gejala umum yang ditampilkan adalah perilaku mengganggu orang lain (Campbell, Shaw, \& Gilliom, 2000 dalam Akhter dkk., 2011). Perilaku internalisasi merupakan perilaku bermasalah dimana perilaku ini ditandai dengan kecemasan, depresi, stres yang dialami oleh anak (Achenbach, 1991 dalam Akhter, 2011; Goodman, 1997).

Terdapat beberapa faktor yang mempengaruhi perilaku bermasalah pada anak, seperti kondisi orangtua dan keadaan di dalam keluarga (Izzaty \& Nuryoto, 2006). Sesuai dengan pendapat Belsky (1984), karakteristik anak dan pengasuhan orangtua dapat mempengaruhi perkembangan anak. Pengasuhan orangtua memiliki peran penting dalam membentuk perilaku anak. Menurut Kenny dan Kenny (1991), gaya pengasuhan merupakan segala sesuatu yang dilakukan orang tua untuk membentuk perilaku anak-anak mereka, hal ini meliputi peringatan dan aturan, pengajaran dan perencanaan, contoh dan kasih sayang serta pujian dan hukuman. Baumrind (2005) mengkategorikan gaya pengasuhan orangtua menjadi tiga, yakni otoriter, otoritatif, dan permisif. Orangtua dengan pengasuhan otoriter cenderung kurang hangat dan terlalu ketat dalam menjalankan aturan. Robinson, Mandleco, Olsen, dan Hart (2001) menyatakan ciri-ciri dari gaya pengasuhan otoriter adalah adanya kekerasan fisik, kekerasan verbal, dan pemberian hukuman oleh orangtua kepada anak. Sebaliknya, orangtua dengan pengasuhan otoritatif cenderung hangat, namun tetap memberikan aturan dan batasan kepada anak (Baumrind, 2005; Santrock, 2014). Ciri-ciri dari gaya pengasuhan otoritatif adalah adanya kehangatan dan dukungan, pemberian alasan atau penjelasan kepada anak mengenai aturan yang dijalankan, serta keterlibatan demokratis, yakni orangtua memperbolehkan anak untuk berpendapat dan memberikan masukan (Robinson dkk., 2001). Sementara itu, orangtua dengan gaya pengasuhan permisif cenderung terlalu hangat dan tidak menetapkan batasan (Baumrind, 2005; Santrock, 2014). Hal ini ditandai dengan sikap orangtua yang memanjakan anak (Robinson dkk., 2001). Penelitian oleh Akhter dan kawankawan (2011) menunjukkan bahwa gaya pengasuhan otoriter dan permisif berhubungan secara positif dengan perilaku bermasalah (internalisasi dan eksternalisasi). Sebaliknya, gaya pengasuhan otoritatif berhubungan secara negatif dengan perilaku bermasalah.

Penelitian yang membahas tentang gaya pengasuhan orangtua dengan perilaku bermasalah belum banyak diteliti pada anak TK. Penelitian Akhter dan kawan-kawan (2011) dilakukan pada anak usia Sekolah Dasar. Oleh karena itu, tujuan dari penelitian ini adalah menguji ada tidaknya hubungan antara gaya pengasuhan orangtua (otoritatif, otoriter, dan permisif) dengan perilaku bermasalah pada anak TK. Hipotesis penelitian adalah ada hubungan yang signifikan antara gaya pengasuhan dengan perilaku bermasalah anak. Diduga bahwa pengasuhan otoritatif berkorelasi negatif dengan perilaku bermasalah anak, sedangkan pengasuhan otoriter dan pengasuhan permisif berkorelasi positif dengan perilaku bermasalah anak.

\section{Metode Penelitian}

Variabel dalam penelitian ini adalah gaya pengasuhan orangtua (variabel independen), dan perilaku bermasalah anak (variabel dependen). Populasi dalam penelitian ini adalah orangtua yang memiliki anak berusia 4-6 tahun di TK X dan TK Y Surabaya. Tidak dilakukan pengambilan sampel dalam penelitian ini, melainkan seluruh orangtua siswa (TK A dan B) diminta kesediaannya untuk berpartisipasi dalam penelitian (total population study). Mereka yang berpartisipasi adalah 71 orangtua. Mayoritas adalah ibu $(91,55 \%)$ dan berlatar belakang pendidikan SMA (30,99\%) dan diploma (33,80\%). Sebagian besar berusia 31-40 
tahun $(54,93 \%)$ dan bekerja $(60,56 \%)$. Kuesioner disampaikan kepada orangtua melalui perantaraan pihak sekolah. Orangtua mengembalikan kuesioner juga melalui pihak sekolah.

Gaya pengasuhan orangtua diukur dengan menggunakan Parenting Style and Dimension Questionnaire (PSDQ; Robinson dkk., 2001) versi singkat yang terdiri dari 32 aitem, yakni 15 aitem pengasuhan otoritatif (aspek kehangatan dan dukungan, pemberian alasan, dan keterlibatan yang demokratis), 12 aitem pengasuhan otoriter (aspek kekerasan fisik, kekerasan verbal, dan pemberian hukuman), dan 5 aitem pengasuhan permisif (aspek memanjakan). Masing-masing aitem terdiri atas 5 pilihan jawaban, yakni dari Tidak Pernah (skoring 1), Jarang (skoring 2), Kadang-Kadang (skoring 3), Sangat Sering (skoring 4), dan Selalu (skoring 5). Sedangkan perilaku bermasalah anak diukur dengan menggunakan Strength and Difficulties Questionnaire (SDQ; Goodman, 1997) yang terdiri dari 20 aitem, terbagi ke dalam 4 aspek (hiperaktivitas, masalah perilaku, masalah emosi, dan masalah teman sebaya) di mana masing-masing aspek terdiri atas 5 aitem dengan 3 pilihan jawaban, yakni: Tidak Benar (skoring 0), Agak Benar (skoring 1), dan Benar (skoring 2). Kedua jenis skala ini diterjemahkan ke dalam bahasa Indonesia. Terjemahan SDQ diambil dari website resmi SDQ, sedangkan PSDQ telah diterjemahkan oleh penulis kedua untuk keperluan penelitian lainnya dan terjemahannya telah direviu oleh individu yang kompeten dalam Bahasa Inggris dan Indonesia. Selain itu, kedua skala telah diujicobakan kepada dua orangtua untuk memastikan bahwa istilah-istilah yang digunakan mudah dipahami.

Berdasarkan uji validitas konstruk pada penelitian terdahulu ditemukan bahwa PSDQ terdiri atas tiga faktor sesuai dengan yang diperkirakan, yakni authoritative, authoritarian, dan permissive (Robinson dkk., 2001). Pada penelitian ini, daya diskriminasi aitem PSDQ adalah 0,213-0,538 untuk pengasuhan otoritatif; 0,287-0,636 untuk pengasuhan otoriter; dan 0,022-0,455 untuk pengasuhan permisif. Kemudian nilai reliabilitas PSDQ dari penelitian sebelumnya adalah 0,86 untuk pengasuhan otoritatif; 0,82 untuk pengasuhan otoriter; dan 0,64 untuk pengasuhan permisif (Robinson, dkk., 2001). Pada penelitian ini, nilai reliabilitasnya adalah 0,770 untuk pengasuhan otoritatif; 0,813 untuk pengasuhan otoriter; dan 0,363 untuk pengasuhan permisif.

Untuk alat ukur SDQ, penelitian terdahulu mengkorelasikan alat ini dengan alat ukur perilaku bermasalah lainnya (Rutter) dan nilai korelasi yang dihasilkan sebesar 0,88 (Goodman, 1997), sehingga dapat disimpulkan bahwa SDQ memiliki validitas kriteria yang baik. Sementara itu, pada penelitian ini, daya diskriminasi aitem yang dihasilkan adalah 0,006-0,562. Kemudian nilai reliabilitas SDQ pada penelitian terdahulu adalah 0,81 (Moriwaki \& Kamio, 2014). Pada penelitian ini, nilai reliabilitas yang dihasilkan adalah 0,76.

Untuk menguji hubungan antara gaya pengasuhan orangtua dengan perilaku bermasalah anak, digunakan teknik korelasi non parametric Kendall's Tau-b. Hal ini disebabkan karena tidak terpenuhinya uji asumsi statistik parametrik, yakni uji normalitas untuk variabel perilaku bermasalah anak, pengasuhan otoriter, dan pengasuhan permisif, dan uji linieritas untuk variabel pengasuhan otoritatif dengan perilaku bermasalah anak.

\section{Hasil Penelitian}

Penelitian ini hendak menguji hubungan antara gaya pengasuhan orangtua dengan perilaku bermasalah anak. Kecenderungan orangtua dalam menerapkan masing-masing gaya pengasuhan (otoritatif, otoriter, dan permisif) diukur dan dikaitkan dengan kemunculan perilaku bermasalah anak usia dini.

Hasil uji hipotesis dengan korelasi Kendall's Tau-b menunjukkan tidak adanya hubungan yang signifikan antara gaya pengasuhan otoritatif orangtua dengan perilaku bermasalah anak, dengan nilai $r$ sebesar $-0,049, p=0,563(p>0,05)$. Sementara itu, korelasi yang signifikan ditemukan antara gaya pengasuhan otoriter dengan perilaku bermasalah anak, $r=0,336, p=0,000(p<0,05)$. Semakin sering gaya pengasuhan otoriter diterapkan, semakin 
tinggi tingkat perilaku bermasalah anak. Selanjutnya, ditemukan adanya hubungan antara gaya pengasuhan permisif dengan perilaku bermasalah anak, dengan nilai $r$ sebesar $0,267, p=$ $0,002(p<0,05)$, sehingga dapat disimpulkan bahwa ada hubungan yang signifikan antara gaya pengasuhan permisif dengan perilaku bermasalah anak.

\section{Diskusi}

Hasil penelitian ini tidak sepenuhnya mendukung hipotesis penelitian. Pengasuhan otoriter dan pengasuhan permisif memang berhubungan secara signifikan dengan perilaku bermasalah anak, namun pengasuhan otoritatif tidak berhubungan signifikan dengan perilaku bermasalah anak. Selanjutnya akan dibahas hasil penelitian ini yang dikontraskan dengan literatur dan hasil penelitian terdahulu.

Adanya hubungan yang signifikan antara gaya pengasuhan otoriter dengan perilaku bermasalah anak sesuai dengan hasil penelitian oleh Israfil (2015). Penelitian tersebut dilakukan pada anak prasekolah dan hasilnya juga menunjukkan adanya hubungan negatif yang signifikan antara pola asuh otoriter dengan perkembangan anak usia dini. Orangtua dengan pengasuhan otoriter biasanya menetapkan aturan serta batasan yang tegas dan tidak memberikan peluang bagi anak untuk berbicara. Anak yang dididik dengan pengasuhan ini seringkali mengalami kecemasan dan masalah sosial. Dampak dari pengasuhan otoriter cenderung negatif, anak mengalami masalah dalam hubungannya dengan orangtuanya sehingga pada saat anak berada di luar rumah, anak cenderung bertindak seenaknya dan berperilaku agresif (Sarwono. 1997).

Pada penelitian ini, gaya pengasuhan permisif berhubungan positif signifikan dengan perilaku bermasalah anak. Hal ini memiliki persamaan dengan hasil penelitian dari Pasaribu (2013) mengenai gaya pengasuhan permisif dan dampaknya pada penurunan karakter jujur dan tanggung jawab. Kejujuran dan tanggung jawab penting dimiliki oleh individu agar dapat berkembang secara positif. Orangtua dengan pengasuhan permisif menunjukkan tingkat kehangatan yang tinggi namun tingkat kontrol yang rendah dan hal ini berdampak pada kurangnya kontrol diri pada anak, sehingga anak kesulitan untuk mencapai tujuannya dan tidak termotivasi untuk berprestasi (Santrock, 2014). Pada penelitian Pasaribu (2013), ditemukan bahwa anak yang diasuh dengan pengasuhan permisif kurang menunjukkan karakter yang jujur dan bertanggungjawab. Dampak yang serupa kemungkinan terjadi dalam penelitian ini karena semakin sering orangtua menerapkan pengasuhan permisif, semakin sering anak memunculkan perilaku bermasalahnya.

Sementara itu, gaya pengasuhan otoritatif dalam penelitian ini tidak memberikan dampak terhadap perilaku bermasalah anak. Hal ini berbeda dengan penelitian sebelumnya mengenai well-being, pengasuhan otoritatif dan perilaku bermasalah pada anak yang berada pada tahap perkembangan remaja (Sumargi \& Kristi, 2017). Salah satu hasil penelitian tersebut menunjukkan hubungan negatif yang signifikan antara gaya pengasuhan otoritatif orangtua dengan perilaku bermasalah remaja. Dijelaskan bahwa dampak dari pengasuhan otoritatif adalah anak memiliki kemampuan untuk meregulasi diri. Orangtua mendorong anak untuk membuat keputusan secara bebas dan berkomunikasi dengan baik. Apabila terjadi masalah, orangtua dan anak dapat berdiskusi dan hal inilah yang mungkin membuat rendahnya perilaku bermasalah anak (Sumargi \& Kristi, 2017). Perbedaan hasil penelitian ini dengan penelitian tersebut mungkin disebabkan adanya perbedaan partisipan penelitian, di mana pada penelitian Sumargi dan Kristi (2017), partisipannya adalah orangtua remaja sedangkan pada penelitian ini partisipannya adalah orangtua anak usia TK. Ada kemungkinan pada anak TK, anak memiliki pemahaman kognitif yang terbatas dan kemampuan komunikasi yang belum berkembang sehingga anak kurang memahami dorongan dari orangtua untuk mengambil keputusan sendiri dan untuk berdiskusi. Menurut Piaget (dalam Olson \& Hergenhahn, 2013), penalaran anak usia dini belum sepenuhnya logis. Anak usia 
dini masuk dalam tahap berpikir pra-operasional dimana mereka secara simbolis dapat melukiskan dunia dengan kata-kata, namun mereka belum mampu untuk melaksanakan tindakan mental yang diinternalisasikan. Sebagai contoh anak-anak belum mampu membedakan perspektif dirinya dengan orang lain (Piaget dalam Santrock, 2014). Oleh karena keterbatasan kognitif anak, maka dibutuhkan ketrampilan orangtua untuk berkomunikasi dengan bahasa yang sederhana yang mudah dipahami oleh anak. Ada kemungkinan orangtua kurang mampu untuk melakukannya sehingga yang terjadi adalah anak tidak paham ketika diajak berdiskusi oleh orangtua. Penelitian selanjutnya dapat menggali lebih mendalam mengenai adanya kemungkinan ini. Lalu perbedaan yang lain adalah jumlah partisipan penelitian, yakni pada penelitian Sumargi dan Kristi (2017), jumlah partisipan adalah 142 orang, sedangkan pada penelitian ini, jumlah orangtua yang terlibat dalam penelitian lebih terbatas (71 orang). Kemungkinan dengan memperbesar jumlah partisipan penelitian, hasil penelitian menjadi lebih akurat.

\section{Kesimpulan dan Saran}

Berdasarkan hasil penelitian di atas dapat disimpulkan bahwa gaya pengasuhan otoritatif tidak memiliki hubungan yang signifikan dengan perilaku bermasalah anak. Sedangkan untuk gaya pengasuhan otoriter dan gaya pengasuhan permisif ditemukan adanya hubungan yang signifikan dengan perilaku bermasalah anak. Semakin sering orangtua menerapkan pengasuhan otoriter dan pengasuhan permisif, maka semakin tinggi tingkat perilaku bermasalah anak. Sebaliknya, semakin jarang orangtua menerapkan pengasuhan otoriter dan permisif, maka semakin rendah tingkat perilaku bermasalah anak.

Berdasarkan hasil penelitian ini maka diberikan saran-saran praktis bagi pihak-pihak yang terlibat dalam pengasuhan dan pendidikan anak, yakni orangtua dan pihak sekolah. Diharapkan orangtua semakin menyadari besarnya pengaruh dari gaya pengasuhan bagi perilaku anak, khususnya gaya pengasuhan otoriter dan permisif. Orangtua perlu mewaspadai penerapan gaya pengasuhan otoriter dan permisif yang terlalu sering pada anak usia dini karena adanya kemungkinan bahwa hal ini dapat meningkatkan perilaku bermasalah anak. Namun perlu disadari pula bahwa pengasuhan gaya otoritatif tidak serta merta menurunkan tingkat perilaku bermasalah anak. Penerapan gaya otoritatif tampaknya harus memperhitungkan kemampuan berpikir dan kematangan kognitif anak. Kemudian, saran juga ditujukan kepada pihak sekolah. Diharapkan pihak sekolah dapat semakin menyadari pentingnya peran orangtua dalam perkembangan anak, khususnya dalam kemunculan perilaku bermasalah anak. Diharapkan pihak sekolah menjalin kerjasama yang erat dengan orangtua demi perkembangan anak yang optimal. Hal ini dapat dilakukan dengan memberikan informasi kepada orangtua melalui seminar dan sejenisnya mengenai dampak negatif dari pengasuhan otoriter dan permisif terhadap perilaku bermasalah anak.

Selanjutnya, diharapkan agar penelitian berikutnya dapat mengantisipasi keterbatasn dalam penelitian ini, antara lain dengan melakukan validasi alat ukur yang digunakan agar aitem-aitemnya sesuai dengan konteks pengasuhan orangtua di Indonesia. Rendahnya nilai reliabilitas dari skala pengasuhan permisif ( $P S D Q$-permissive) mungkin menandakan aitemaitem yang digunakan kurang mencerminkan konsep pengasuhan dalam budaya Indonesia. Penelitian selanjutnya juga diharapkan dapat melibatkan lebih banyak orangtua anak prasekolah sehingga hasil penelitian dapat digeneralisasikan lebih luas lagi. Jika memungkinkan peneliti dapat menyebarkan kuesioner kepada orangtua secara langsung (tanpa melalui perantara siapapun) sehingga apabila ada pertanyaan seputar kuesioner (misalnya orangtua kurang paham dengan isi aitem), maka peneliti dapat segera menjawabnya. Selain itu, penelitian selanjutnya dapat melihat faktor-faktor lain yang dapat mempengaruhi keterkaitan antara gaya pengasuhan dengan perilaku, seperti kematangan kognitif anak. Penelitan dapat pula diarahkan untuk menguji ada tidaknya perbedaan antara 
gaya pengasuhan orangtua dari anak usia dini dengan orangtua dari anak yang sudah beranjak remaja. Hal ini dimaksudkan untuk melihat sejauhmana masing-masing gaya pengasuhan dipengaruhi oleh tahap perkembangan anak.

\section{Daftar Pustaka}

Akhter, N., Hanif, R., Tariq, N., \& Atta, M. (2011). Parenting style as predictors of externalizing and internalizing behavior problems among children. Pakistan Journal of Psychological Research, 26(1), 23-41.

Baumrind, B. (2005). Pattern of parental authority and adolescent autonomy. New direction for child and adolescent development, 108, 61-69. doi: 10.1002/cd.128.

Belsky, J. (1984). The determinants of parenting: a process model. Child Development, 55(1), 83-96. doi: /10.2307/1129836

Goodman, R. (1997). The Strengths and Difficulties Questionnaire: a research note. Journal Child Psychology \& Psychiatry, 38(5), 581-586. doi: 10.1111/j.14697610.1997.tb01545.x

Hurlock, E.B. (1997). Psikologi perkembangan: Suatu pendekatan rentang kehidupan.(Edisi kelima). Jakarta: Erlangga.

Israfil (2015). Hubungan pola asuh orangtua dengan perkembangan anak usia prasekolah. Dalam Latipun, D. Karmiati, \& R.N. Anganthi (Eds.). Prosiding seminar nasional psikologi dan kemanusiaan (hal. 175-179). Malang: Universitas Muhammadiyah Malang. Diambil dari web : http://mpsi.umm.ac.id/files/file/175-179\%20Israfil.pdf

Izzaty, R.E., \& Nuryoto, S. (2006). Prediktor permasalahan perilaku anak usia TK. Sosiosains, 19(3), 325-328.

Kenny, J., \& Kenny, M. (1991). Dari bayi sampai dewasa. Jakarta: PT BPK Gunung Mulia.

Moriwaki, A. \& Kamio, Y. (2014). Normative data and psychometric properties of Strengths and Difficulties Questionnaire among Japanese school-aged children. Child Adolescent Psychiatry and Mental Health, 8(1), 1-12. doi: 10.1186/1753-2000-8-1

Olson, M.H. \& Hergenhahn, B.R. (2013). An Introduction to: Theories of Learning. (Ninth Edition). New York: Routledge.

Pasaribu, R.M., Hastuti, \& Alfiasari (2013). Gaya pengasuhan permisif dan rendahnya sosialisasi nilai dalam keluarga berisiko terhadap penurunan karakter remaja. Jurnal Ilmu Keluarga dan Konsumen, 6(3), 163-171.

Spoth, R., Neppl, T., Lillehoj, C.G., \& Jung, T., (2006). Gender-related quality of parentchild interactions and early adolescent. Journal of Family Issues, 27(6), 826-849. doi: $10.1177 / 0192513$ X05285614

Santrock, J. W. (2014). Psikologi pendidikan, Educational psychology. (Edisi 5, Buku 1). Jakarta: Salemba Humanika.

Sarwono, S. W. (1997). Psikologi sosial: Individu \& teori-teori psikologi sosial. Jakarta: PT Balai Pustaka.

Sumargi, A. M., \& Kristi, A. N. (2017). Well-being orangtua, pengasuhan otoritatif, dan perilaku bermasalah pada remaja. Jurnal Psikologi, 44(3), 185-197. doi: 10.22146/jpsi.25381

Robinson, C. C., Mandleco, B., Olsen, S. F., \& Hart, C. H. (2001). The Parenting Styles and Dimensions Questionnaire (PSDQ). Dalam B. F. Perlmutter, J.Touliatos, \& G. W. Holden (Eds.), Handbook of family measurement techniques (hal. 319 - 321). Thousand Oaks, California: Sage Publications, Inc. 
Jurnal Experientia Volume 7, Nomor 1 Juli 2019 